\title{
Consensus recommendations on the diagnosis and treatment of hepatitis c virus infection in sub Saharan Africa
}

\begin{abstract}
Sub-Saharan Africa has a high burden of hepatitis C virus (HCV) infection. Therefore, 10 experts from Africa convened, reviewed the literature, and provided recommendations to optimize the diagnosis; management; and pre-, on- and posttreatment assessment of HCV infection in Africa. The panel recommended initial anti$\mathrm{HCV}$ testing, followed by qualitative $\mathrm{HCV}$ RNA assay/core antigen testing for $\mathrm{HCV}$ diagnosis. The panel suggested that genotype testing may help in treatment selection; however, use of pan-genotypic regimens (sofosbuvir-velpatasvir) may obviate the need for genotyping. The recommended pre-treatment assessments include tests for hepatic/ renal function; hepatitis B surface antigen; HIV; non-invasive fibrosis assessment; and testing for hepatocellular carcinoma. The panel provided an overview of the use of available antiviral agents (sofosbuvir, ledipasvir, daclatasvir and velpatasvir) for treatment of HCV GT1-GT6 infections. This consensus document may help guide clinicians to effectively use the available antiviral agents and optimize diagnosis and treatment of HCV infection in Africa.
\end{abstract}

Keywords: hepatitis C virus, treatment, consensus, sub-Saharan Africa
Volume 10 Issue 4 - 2019

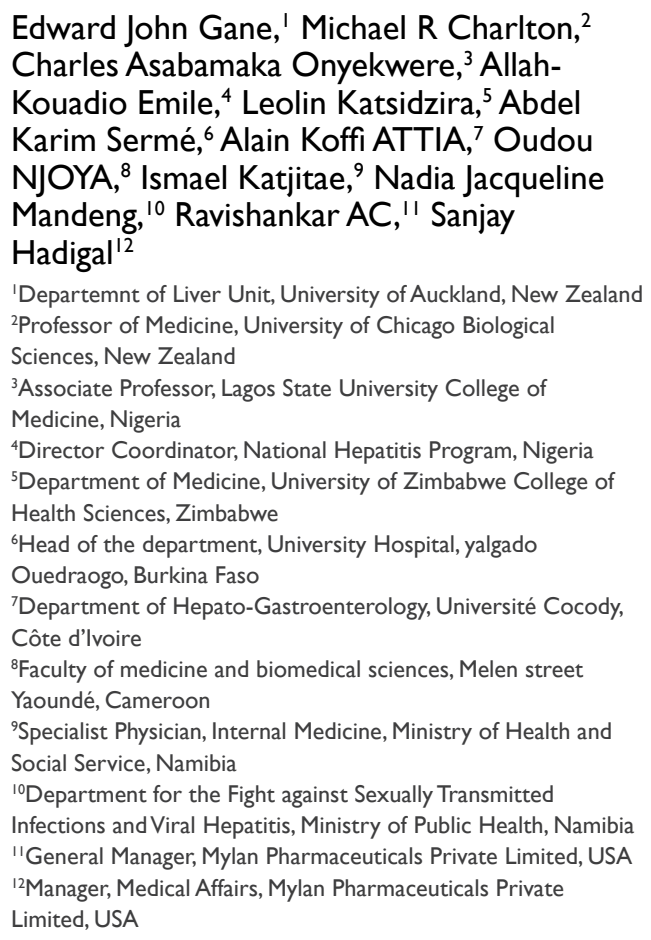

Correspondence: Edward John Gane, Liver Unit, University of Auckland, Auckland, 1010, New Zealand, Tel 642154837I, Email edgane@adhb.govt.nz

Received: June 26, 2019 | Published: July 12, 2019

\section{Introduction}

Hepatitis $\mathrm{C}$ virus (HCV) belongs to the genus Hepacivirus of the family Flaviviridae ${ }^{1}$ and is classified into 6 major genotypes (GT1GT6). ${ }^{2}$ An expanded classification of HCV reveals a new genotype, GT7. ${ }^{3,4}$

According to the 2017 World Health Organization (WHO) global hepatitis report, there were a total of 1.75 million new HCV infections, worldwide in 2015, and the global prevalence of $\mathrm{HCV}$ infection was noted to be about $1 \%$ ( 71 million). Of the 71 million individuals living with $\mathrm{HCV}$ infection globally in 2015, about 11 million were from the African region. ${ }^{5}$ In the latest country-level HCV disease burden model developed by the Polaris Observatory $\mathrm{HCV}$ collaborators that estimated the prevalence of $\mathrm{HCV}$ infection in 113 countries, the global prevalence of viremic HCV infection in 2015 was found to be close to the WHO estimates, at 1.0\% $(71.1$ million viremic $\mathrm{HCV}$-infected individuals). The overall prevalence of viremic $\mathrm{HCV}$ infection in the sub-Saharan African region was found to be $4.6 \%$ (10.1million viremic HCV infected individuals). Four major sub-Saharan regions were included in this model, including-(1) Central sub-Saharan Africa; (2) East sub-Saharan Africa; (3) Southern sub-Saharan Africa (South Africa); and (4) West sub-Saharan Africa. The prevalence of viremic HCV infection in Central, West, Southern and East sub-Saharan Africa was found to be $2.1 \%, 1.3 \%, 0.7 \%$, and $0.5 \%$, respectively. ${ }^{6} \mathrm{~A}$ similar $\mathrm{HCV}$ prevalence pattern, with high rates in the Middle Africa region, and low rates in Southern Africa, was reported in another systematic review and meta-analysis of 184 nation-level estimations across Africa. ${ }^{7}$ Other systematic reviews and meta-analyses on the prevalence of $\mathrm{HCV}$ infection across countries in West and Central sub-Saharan Africa have also revealed a high seroprevalence of $\mathrm{HCV}$ in these regions. ${ }^{8,9}$ 
In the Polaris Observatory report, the GT distribution was analyzed for 115 countries, and it was noted that about $44 \%$ of global HCV cases were GT1, followed by GT3 (25\%), and GT4 (15\%). In Africa, the most prevalent GT in the Central, West, Southern and East sub-Saharan regions was noted to be GT4, GT1, GT5 and GT4, respectively. A wide variation in the GT distribution was noted within some regions in Africa. In the West sub-Saharan African belt, while regions such as Nigeria had a high prevalence of GT1; others including Ghana, The Gambia, Guinea Bissau and Burkina Faso had a high prevalence of GT2; Chad had a high prevalence of GT4; and Cameroon had high prevalence of both GT1 and GT4. ${ }^{6}$

In addition to the diversity in $\mathrm{HCV}$ prevalence and GT distribution across various regions of Africa, high genetic diversity has been observed in the most common genotype of the region, GT4. ${ }^{10}$ Furthermore, robust epidemiological and GT prevalence data are lacking, as all the countries in the region have not contributed to the national GT distribution data in most of the available large-scale epidemiological studies. ${ }^{6,10}$ In the absence of robust prevalence data which forms the very basis for the development of healthcare policy, efficient management of the disease cannot be achieved. . $^{7,11}$

Several other unmet needs and challenges have been reported in the literature on the management of $\mathrm{HCV}$ infection in Africa, including: (1) lack of proper surveillance, resulting in inaccurate estimation of the burden of HCV infection; ${ }^{12}$ (2) emergence of resistant GT $5 \mathrm{HCV}$ infections; ${ }^{13}$ (3) emergence of GT7; ${ }^{14}$ (4) dearth of cost-effective, rapid diagnostic tests; (5) reduced efforts from patient's end to access

Table I Definitions of the grading of the recommendations
HCV treatment due to threat of stigmatization, and discrimination; ${ }^{15}$ (6) licensing, patent and cost aspect of direct-acting antiviral (DAA) therapy: ${ }^{16}(7)$ use of unlicensed generics with low efficacy; ${ }^{17,18}(8)$ lack of universal treatment coverage for HCV patients; ${ }^{16}$ and (9) non-responsiveness of patients to DAA treatment. ${ }^{19,20}$ Development of structured nation-specific $\mathrm{HCV}$ treatment guidelines/strategies has also been cited a crucial need of the hour in the African region. ${ }^{12}$ In this context, it is pertinent to mention that there is no clear latest consensus on the diagnosis, management, and monitoring of HCV infection, specific to the African region. Hence, the objective of the current consensus document is to guide clinicians on the diagnosis and management of chronic HCV infection in the resource-limited settings of Africa to ensure optimal clinical outcomes.

\section{Methodology of consensus development}

In April 2018, a panel of ten experts in the field of hepatology from Africa convened to review the updated literature on the management of $\mathrm{HCV}$ infection and provide recommendations to optimize the:

a. Diagnosis of $\mathrm{HCV}$ infection

b. Use of cost-effective treatments for the management of $\mathrm{HCV}$ infection in Africa

c. Pre-, on-, and post-treatment assessments during HCV management

The recommendations for the use of optimal treatment regimens in the management of $\mathrm{HCV}$ infection were graded by the expert panel as Preferred, Alternative, or Not Recommended (Table 1).

\section{Grading of the \\ recommendation}

Preferred

Alternative

\section{Definition of the grading}

Treatment can be used in most patients and recommendation is based on optimal efficacy, favorable tolerability and toxicity profiles, duration, and pill burden.

Treatment can be the one that is effective but with potential disadvantages/limitations for use in certain patient populations or with less supporting data as compared with the recommended regimens. In certain situations, an alternative regimen may be an optimal regimen for a specific patient situation.
Not recommended
Treatment is clearly inferior compared with the recommended or alternative regimens because of factors such as lower efficacy, unfavorable tolerability and toxicity, longer duration, and/or higher pill burden. Unless otherwise indicated, such regimens should not be administered to patients with HCV infection.

\section{Diagnosis of HCV infection}

Initial HCV serological testing is recommended by several current guidelines for the detection of anti-HCV antibodies. ${ }^{21-23}$ The chronic nature of the infection may be further confirmed by a sensitive nucleic acid diagnostic assay for the detection of HCV RNA. ${ }^{22}$ The use of a qualitative HCV RNA assay may be considered as a feasible option for providing broader access to HCV diagnosis and care in low- and middle-income countries, especially if pan-genotypic therapies are available (Box 1). Quantification of HCV core antigen, a surrogate marker of HCV replication, may also be used instead of the HCV RNA test for the diagnosis of HCV infection. The lower sensitivity of the core antigen test (lower limit of detection $3 \log _{10} \mathrm{IU} / \mathrm{mL}$ ) makes this test less useful in detecting early infection or HCV clearance.
However, the $\mathrm{HCV}$ core antigen test is suitable for confirming established chronic HCV infection and for determining sustained virological response or cure post-treatment. An initial negative HCV serological test result does not indicate the absence of $\mathrm{HCV}$ infection; negative test result may be possible in cases of acute infection, in immunocompromised patients, or in patients on dialysis. In these patients, HCV RNA testing may be considered as a part of the initial assessment for the diagnosis of $\mathrm{HCV}$ infection. ${ }^{22}$

The severity of liver disease is a key factor in planning initial treatment and further follow-up evaluation of patients. ${ }^{21,24}$ Patients with confirmed HCV infection should be evaluated to assess the degree of liver fibrosis and cirrhosis by liver biopsy or other non-invasive tests. ${ }^{25}$ The utility of liver biopsy is limited by the cost, invasiveness, 
and the risk of complications. Non-invasive tests have replaced liver biopsy to estimate the extent of liver disease in patients with chronic viral hepatitis in most countries. The most widely used noninvasive test is transient elastography (Fibroscan ${ }^{\circledR}$ ), but availability and cost constraints may limit the use of elastography in resource-limited settings. ${ }^{23}$ In case of unavailability of transient elastography, the AST-to-platelet ratio index (APRI) or fibrosis-4 (FIB-4) index score may be useful in liver fibrosis assessment. ${ }^{21}$ Additionally, testing for $\mathrm{HCV}$ genotype is recommended before treatment initiation to tailor the treatment strategy to suit the patient..$^{21,23,24}$ It is pertinent to mention here, that the use of pan-genotypic treatment regimens such as velpatasvir-based regimens obviates the need for HCV genotype testing prior to initiating treatment (Box 1). Hence, pan-genotypic regimens significantly reduce the total cost of diagnosis of $\mathrm{HCV}$ infection, which is an added advantage in developing countries. ${ }^{26}$

\section{Consensus recommendations for the diagnosis of HCV infection}

i. Anti-HCV testing is recommended for screening/initial testing, and if the result is positive, current infection should be confirmed by a sensitive HCV RNA/core antigen testing.

ii. Qualitative HCV RNA testing is a reasonable, good, and costeffective method, and can replace quantitative testing.

iii. Genotyping is recommended to guide selection of the most suitable antiviral regimen.

iv. A pan-genotypic regimen such as sofosbuvir-velpatasvir therapy may obviate the need for genotyping.

\section{Screening of HCV infection}

Serological testing for $\mathrm{HCV}$ may be offered to high-risk individuals, and those with a history of $\mathrm{HCV}$ risk exposure or behavior such as the following: (1) individuals who have undergone medical or dental interventions in settings with inappropriate infection-control practices; (2) individuals who have received blood transfusions without HCV serological testing of the donated blood; (3) patients on hemodialysis; (4) people who inject drugs (annual testing is recommended); (5) individuals who have had tattoos, body piercing, or scarification procedures done with inappropriate infection-control practices; (6) children born to mothers infected with $\mathrm{HCV}$; (7) individuals with human immunodeficiency virus (HIV) infection (annual testing is recommended for HIV+ men who have unprotected sex with men); (8) individuals who use/have used intranasal illicit drugs; (9) commercial sex workers; (10) prisoners and previously incarcerated individuals, $;^{21,23,25}$ (11) women who have undergone genital excision; ${ }^{27}(12)$ men with a history of non-medical circumcision, ${ }^{28}$ and (13) patients with liver disease from any cause. ${ }^{21}$ Rapid 'point-of-care' (POC) anti-HCV antibody diagnostic tests employing serum, plasma, fingerstick whole blood, or saliva may be used as alternatives to standard enzyme immunoassays as a part of the screening programs. ${ }^{22}$ Rapid POC HCV RNA tests are available in Africa such as Cepheid GenXpert ${ }^{\mathbb{Q}}$, where these are already in use as POC TB and HIV diagnostic tests.

\section{Treatment of HCV infection}

The main aim of HCV treatment should be to attain sustained virologic response (SVR). Further, the subsequent reduction in all cause-mortality and prevention of liver-associated adverse effects, end-stage liver disease, hepatocellular carcinoma (HCC), and severe extrahepatic manifestations should also be a part of the treatment goals for the management of $\mathrm{HCV}$ infection..$^{21,24}$

\section{Pre-treatment assessments}

Selection of treatment for the management of HCV infection may be optimized by assessing the liver disease severity and virologic parameters before starting the treatment. Other factors that should be assessed include alcoholism, co-infection with hepatitis B virus or HIV, renal impairment, diabetes mellitus, autoimmunity, and cardiac diseases. $^{22}$

Patients with hepatitis B virus (HBV)-HCV co-infection have been noted to have accelerated progression of liver disease and an increased risk of HCC. ${ }^{29,30}$ Furthermore, HBV reactivation has been found to occur during treatment of $\mathrm{HCV}$ infection with DAAs in these individuals. ${ }^{31,32}$ However, HBV reactivation may be rare among patients with resolved HBV infection..$^{33}$ Therefore, the expert panel recommended that all $\mathrm{HCV}$ patients should be tested for hepatitis B surface antigen (HBsAg) prior to initiating HCV DAA treatment, and all HBV-HCV co-infected patients who test positive for HBsAg, particularly those with quantifiable HBV DNA (increase in HBV DNA by at least $1 \log$ and elevation in alanine transaminase [ALT] $>$ Upper limit of normal [ULN]) should be initiated on HBV antiviral treatment (Box 2). ${ }^{33}$

Patients with $\mathrm{HCV}$ infection, especially those with cirrhosis, are at a higher risk of developing HCC. Hence, HCC surveillance through simple and cost-effective alfa-fetoprotein (AFP) test is recommended in addition to liver ultrasound (Box 2). ${ }^{23,34}$ Furthermore, assessment of HCV RNA or HCV core antigen before initiation of treatment, staging of cirrhosis or fibrosis and assessment of potential drug-drug interactions are also important. Transient elastography, and/or noninvasive serum markers may be used to assess advanced liver fibrosis. Genotype assessment is recommended to individualize the treatment dose and duration which will further help optimize the treatment outcomes. ${ }^{21,22,24}$ However, as discussed above, with the use of pangenotypic treatment regimens (such as velpatasvir-based regimens), the need for HCV genotype testing is obviated. ${ }^{26}$

\section{Consensus recommendations on pre-treatment assessments}

i. Liver fibrosis assessment: The use of transient elastography or non-invasive serum markers is recommended for deciding on the regimen and the need for initiating additional measures for the management of cirrhosis (e.g., HCC screening)

ii. Assessment for potential drug-drug interactions with concomitant medications

iii. The following laboratory tests are recommended:

a. Complete blood count (CBC)

b. Hepatic function tests (albumin, total and direct bilirubin, ALT, aspartate aminotransferase [AST], and alkaline phosphatase levels)

c. Calculated glomerular filtration rate (GFR)

d. HBsAg

e. HIV testing

f. AFP in patients with cirrhosis 


\section{Who should be treated?}

All patients with chronic HCV infection should be considered for treatment, except those with limited lifespan, in whom HCV eradication will provide no benefit. Patients with decompensated cirrhosis should be referred to a tertiary care center and managed by experts with relevant clinical experience. Additionally, factors influencing the decision to treat are: the age of the patient, occupations with a high risk of transmission to others, impact on quality of life, co-morbidities and the potential for the occurrence of serious side effects. ${ }^{21,24}$

\section{Direct-acting antiviral agents available in Africa}

Ribavirin and pegylated interferon (Peg-IFN) were the preferred treatment regimens for $\mathrm{HCV}$ infection before the advent of DAAs. The agents used earlier were inconvenient, with the need to administer injections for up to one year, and had an unpleasant adverse-effect profile, along with low cure rates; the resulting treatment uptake was very poor $(<1 \%$ in most countries). The management of chronic $\mathrm{HCV}$ has noticeably improved with the introduction of DAAs. Currently, three classes of DAAs are in use: second-generation NS3/4 serine protease inhibitors, NS5A inhibitors, and NS5B polymerase inhibitors. Drugs from two of these specified classes are used as various combination regimens for the management of $\mathrm{HCV}$ in the African region. ${ }^{14}$ The DAA regimens available in various African countries, along with their key pharmacological properties, were summarized by the expert panel, as shown in Table $2 .{ }^{35,36,37,38}$ The DAA regimens are also used in combination with ribavirin, which is a nucleoside analog available as a $200 \mathrm{mg}$ tablet. The dose of ribavirin is dependent on the patient's body weight and HCV genotype. Dose reduction or discontinuation of ribavirin is recommended in patients who experience adverse reactions or renal impairment. ${ }^{39}$

\section{Treatment of patients with HCV GTI infection}

Four regimens have been proposed for the treatment of patients with chronic HCV GT1 infection (Table 3).

Table 2 Direct-acting antiviral treatment regimens:Availability in specific African countries and key pharmacological properties

\begin{tabular}{|c|c|c|c|c|c|}
\hline & \multirow{2}{*}{ Country } & \multicolumn{4}{|l|}{ DAA regimens } \\
\hline & & SOF & LDV/SOF & DCV & SOF/VEL \\
\hline \multirow{9}{*}{ 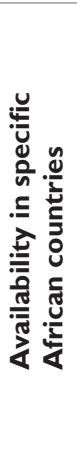 } & Ivory Coast & $\sqrt{ }$ & $\sqrt{a}$ & $\sqrt{a}$ & $\sqrt{\mathrm{a}}$ \\
\hline & Cameroon & $\sqrt{\mathrm{a}}$ & $\sqrt{ } \mathrm{a}$ & $\sqrt{a}$ & $\sqrt{\mathrm{a}}$ \\
\hline & Burkina Faso & $\sqrt{\mathrm{a}}$ & $\sqrt{a}$ & $\sqrt{a}$ & $\sqrt{\mathrm{a}}$ \\
\hline & Senegal & $\sqrt{\mathrm{a}}$ & $\sqrt{ } \mathrm{a}$ & $\sqrt{a}$ & $\sqrt{\mathrm{a}}$ \\
\hline & Zimbabwe & $\sqrt{ }$ & $\sqrt{b}$ & & $\sqrt{b}$ \\
\hline & Namibia & & & & \\
\hline & Nigeria & & $\sqrt{ }$ & & \\
\hline & Ghana & $\sqrt{ }$ & $\sqrt{ }$ & $\sqrt{ }$ & $\sqrt{b}$ \\
\hline & Mode of action & $\begin{array}{l}\text { Inhibition of HCV NS5B } \\
\text { RNA-dependent RNA } \\
\text { polymerase }\end{array}$ & $\begin{array}{l}\text { LDV: Inhibition of } \\
\text { HCV NS5A protein }\end{array}$ & $\begin{array}{l}\text { Inhibition of } \\
\text { HCV NS5A } \\
\text { protein }\end{array}$ & $\begin{array}{l}\text { VEL: Inhibition of } \\
\text { HCV NS5A protein }\end{array}$ \\
\hline & Dose & $400 \mathrm{mg}^{\mathrm{c}}$ & $\begin{array}{l}\text { FDCc: } 90 \mathrm{mg} \\
\text { LDV+400mg SOF }\end{array}$ & $60 \mathrm{mg}^{\mathrm{c}}$ & $\begin{array}{l}\text { FDCc: } 100 \mathrm{mg} \\
\text { VEL+400mg SOF }\end{array}$ \\
\hline & Cmax & $0.5-2 \mathrm{~h}$ & LDV: 4-4.5h & $2 \mathrm{~h}$ & VEL: $3 h$ \\
\hline & Major elimination route & Renal & LDV: Biliary & Faeces & VEL: Biliary \\
\hline $\begin{array}{l}\frac{y}{1} \\
\frac{0}{0} \\
0 \\
0\end{array}$ & $\begin{array}{l}\text { Dose adjustment } \\
\text { recommendations in } \\
\text { renal impairment }\end{array}$ & $\begin{array}{l}\text { Not recommended } \\
\text { for use in severe } \\
\text { impairment }^{d}\end{array}$ & $\begin{array}{l}\text { Not recommended } \\
\text { for use in severe } \\
\text { impairment }^{d}\end{array}$ & None & $\begin{array}{l}\text { Not recommended } \\
\text { for use in severe } \\
\text { impairment }^{d}\end{array}$ \\
\hline$\frac{\sqrt{\frac{0}{60}}}{0.0}$ & $\begin{array}{l}\text { Dose adjustment } \\
\text { recommendations in } \\
\text { hepatic impairment }\end{array}$ & None & None & None & None \\
\hline 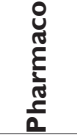 & Drug interactions & $\begin{array}{l}\text { P-gp inducers, } \\
\text { amiodarone }\end{array}$ & $\begin{array}{l}\text { P-gp inducers, } \\
\text { amiodarone }\end{array}$ & $\begin{array}{l}\text { Strong CYP3A } \\
\text { inhibitors, } \\
\text { moderate } \\
\text { CYP3A inducers }\end{array}$ & $\begin{array}{l}\text { P-gp inducers, }{ }^{e} \text { CYP } \\
\text { enzyme inducers }\end{array}$ \\
\hline
\end{tabular}

${ }^{a}$ Available through import permit; ${ }^{\mathrm{b}}$ Available under special access; ' $O$ rally, once-daily, without regard to food; ${ }^{\mathrm{d}} \mathrm{eGFR}<30 \mathrm{ml} / \mathrm{min} / \mathrm{I} .73 \mathrm{~m}{ }^{2}$; ${ }^{\mathrm{E}}$ Examples include rifampin and St John's wort.

DCV, Daclatasvir; LDV, ledipasvir; SOF, sofosbuvir; VEL, velpatasvir; Cmax, peak plasma concentration; eGFR, Estimated glomerular filtration rate; P-gP,

P-glycoprotein; CYP, Cytochrome P; HCV, hepatitis C virus; RNA, ribonucleic acid 
Table 3 Recommended treatment regimens for HCV GTI infection

\begin{tabular}{lll}
\hline $\begin{array}{l}\text { Recommendation } \\
\text { category }\end{array}$ & $\begin{array}{l}\text { Treatment } \\
\text { option/s }\end{array}$ & Treatment regimens \\
\hline
\end{tabular}

I. SOF+VEL $\pm R B V^{\#}$

Preferred i. SOF+VEL for I2weeks (Addition of RBV may be considered in difficult to-treat [treatment-experienced, cirrhotic] patients)

ii. In patients with decompensated cirrhosis (currently treated hepatic encephalopathy or ascites or Child-Pugh-Turcotte class B or C): SOF+VEL+weight-based RBV for I 2 weeks

\begin{tabular}{|c|c|c|c|}
\hline & $\begin{array}{l}\text { 2. } \mathrm{LDV}+\mathrm{SOF} \pm \\
\mathrm{RBV}^{\#}\end{array}$ & $\begin{array}{l}\text { iii. } \\
\text { iv. }\end{array}$ & $\begin{array}{l}\text { LDV+SOF for I } 2 \text { weeks } \\
\text { In treatment-naïve patients with HCV RNA }<6 \text { million IU/mL in whom cirrho- } \\
\text { sis has been conclusively ruled out by transient elastography (Fibroscan) or } \\
\text { biopsy: LDV+SOF for } 8 \text { weeks } \\
\text { In treatment-experienced cirrhotic patients/patients with decompensated } \\
\text { liver disease/post-liver transplant patients: LDV+SOF+RBV for I } 2 \text { weeks OR } \\
\text { LDV+SOF for } 24 \text { weeks if RBV is ineligible }\end{array}$ \\
\hline Alternative & $\begin{array}{l}\text { I. SOF+DCV } \pm \\
\mathrm{RBV}^{\#}\end{array}$ & $\begin{array}{r}\text { vi. } \\
\text { vii. } \\
\text { viii. }\end{array}$ & $\begin{array}{l}\text { SOF+DCV for I } 2 \text { weeks (Addition of RBV may be considered if cirrhosis has } \\
\text { not been conclusively ruled out) } \\
\text { In patients with compensated cirrhosis: SOF+DCV } \pm \text { weight-based RBV for } \\
24 \text { weeks } \\
\text { In patients with decompensated cirrhosis: SOF+DCV+RBV for } 12 \text { weeks (OR) } \\
\text { SOF+DCV for } 24 \text { weeks if RBV is ineligible }\end{array}$ \\
\hline
\end{tabular}

\section{DCV, Daclatasvir; GT, genotype; HCV, Hepatitis C virus; LDV, Ledipasvir; RBV, Ribavirin; RNA, Rribonucleic acid; SOF, sofosbuvir;VEL,Velpatasvir.}

\#RBV to be dosed as per body weight.

\section{Sofosbuvir + velpatasvir \pm ribavirin}

The findings from the phase III, double-blind, placebo-controlled, randomized ASTRAL-1 trial formed the foundation for the use of sofosbuvir plus velpatasvir regimen for the treatment of patients with HCV GT1 infection. This study enrolled treatment-naïve and previously treated patients with HCV GT1, GT2, GT4, GT5, or GT6 infections, including those with compensated cirrhosis. The enrolled patients were randomized (in a 5:1 ratio) to receive either velpatasvir or sofosbuvir combination $(n=624)$, or placebo $(n=116)$. Treatment with the velpatasvir and sofosbuvir combination for 12 weeks resulted in an overall 99\% SVR (98\% and 99\% SVR in GT1a and GT1b patients, respectively). The safety of the combination was comparable to placebo. ${ }^{40}$ The ASTRAL-4 is another phase III, open-label study that was conducted among treatment-naïve and -experienced HCV patients with GT1 through GT6 infections (n=267; GT1: 78\%) and decompensated cirrhosis. Patients received sofosbuvir and velpatasvir for 24 weeks $(n=90)$, or sofosbuvir and velpatasvir once daily with $(n=87)$ or without $(n=90)$ ribavirin for 12 weeks. The corresponding SVR rates in GT1a-infected patients were $93 \%, 94 \%$, and $88 \%$, respectively, and in GT1b-infected patients $88 \%, 100 \%$, and $89 \%$, respectively. ${ }^{41}$ ASTRAl-5 was another phase III, single-arm study in HCV GT1 through GT6 patients with HIV-1 co-infection, including those with compensated cirrhosis. In this study, sofosbuvir and velpatasvir regimen given for 12 weeks was found to be safe and resulted in a $95 \%$ SVR in GT1 patients. ${ }^{42}$ Furthermore, a review of
23 randomized clinical trials concluded sofosbuvir+velpatasvir with/ without ribavirin regimen, to be effective for the treatment of patients with HCV across GT 1 to 6 infections. ${ }^{43}$ In HCV patients on 12 or 24weeks sofosbuvir/velpatasvir with/without ribavirin, the ribavirinfree regimen was found to be associated with improved patientreported outcomes. ${ }^{44}$

\section{Sofosbuvir + ledipasvir \pm ribavirin}

The phase III ION-1 trial evaluated a regimen of sofosbuvir and ledipasvir (taken for 12 or 24weeks) in treatment-naïve patients with chronic HCV GT1 infection ( $\mathrm{n}=865 ; 16 \%$ with cirrhosis). The study findings revealed that the regimen was highly effective with a $97 \%-99 \%$ SVR.${ }^{45}$ In the ION-3 trial, a combination of sofosbuvir and ledipasvir for a duration of 8 weeks resulted in high SVR rates of $94 \%$ in previously untreated patients with HCV GT1 infection without cirrhosis. The SVR rates with the 8-week regimen were comparable with the 12-week sofosbuvir and ledipasvir combination regimen or the 8-week sofosbuvir and ledipasvir combination regimen with ribavirin. Furthermore, the sofosbuvir and ledipasvir combination was found to be safe and tolerable. ${ }^{46} \mathrm{~A}$ retrospective analysis of $100 \mathrm{chronic}$ HCV patients from the ION-1 trial who achieved SVR at 12weeks post-treatment with sofosbuvir/ ledipasvir with or without ribavirin revealed that the ribavirin-free regimen was associated with reduced fatigue-related patient-reported outcomes ${ }^{47}$ In a separate open label, single center study conducted among HCV GT1 or 4 patients who were receiving treatment for sickle cell disease, sofosbuvir and ledipasvir 
combination for 12- or 24-weeks duration was found to be safe. ${ }^{48} \mathrm{~A}$ recent prospective study (SHARED trial) evaluated the combination of sofosbuvir and ledipasvir in GT1/4 HCV patients and found an $86.7 \%$ SVR rate with the 12-week regimen. Additionally, the study showed the combination to be safe with an adherence rate $>98 \%{ }^{49}$ Recent findings from another international, non-randomized pilot study in GT1, 2 and 4 treatment-naïve HCV patients revealed 100\% adherence to the sofosbuvir and ledipasvir combination and reported an SVR of $90 \%$ for GT1 HCV subtype patients. The combination was also found to be safe and effective in HIV co-infected patients. ${ }^{50}$ The ION-4 multicentric open label trial reported an SVR rate of $>95 \%$ in treatment-naïve and experienced patients with

\section{HCV GT1 infection co-infected with HIV-1. ${ }^{51}$}

Sofosbuvir and ledipasvir regimen with or without ribavirin for 12 or 24 weeks has been found to yield high SVR rates in treatmentexperienced patients, including those with cirrhosis in the ION2 and SIRIUS trials. ${ }^{52,53}$ Another meta-analysis also supports the effectiveness and safety of sofosbuvir and ledipasvir combination in patients with HCV GT1 infection, both treatment-naïve and experienced, including in those with cirrhosis. Further, this analysis indicates that the addition of ribavirin may increase the incidence of adverse events but does not significantly affect the SVR at 12 weeks. ${ }^{54}$

\section{Sofosbuvir+ daclatasvir \pm ribavirin}

The regimen in focus was evaluated in treatment-naïve patients with HCV GT1 through GT3 infection for a duration of 24weeks and in treatment-experienced patients with GT1 infection for 12 or 24weeks in the open-label, AI444040 trial. The SVR rates was $98 \%$, both in treatment-naïve and -experienced patients with GT1 infection. ${ }^{55}$ The open-label, phase III ALLY-1 trial enrolled patients with HCV of all genotypes. Treatment of the enrolled patients with daclatasvir plus sofosbuvir with ribavirin for 12 or 24 weeks in this trial was safe and exhibited an SVR rate of $82 \%$ in GT1 patients with cirrhosis and $95 \%$ in GT1 transplant recipients. ${ }^{56}$ The 24 weeks duration regimen of this combination was found to be safe and effective in recurrence of HCV GT1 cases, post liver transplantation, including those with HIV1 co-infection or with decompensated cirrhosis. ${ }^{57}$ Studies conducted in real-world settings also support the efficacy and safety of this regimen for HCV GT1 infection in diverse population with severe liver disease..$^{58,59}$

\section{Treatment of Patients with HCV GT2 Infection}

Four regimens were proposed by the panel for the treatment of patients with chronic HCV GT2 infection (Table 4).

\section{Sofosbuvir + velpatasvir \pm ribavirin}

In the randomized, phase III, open-label ASTRAL 2 trial, treatment-naïve and -experienced patients with GT2 infection, including those with compensated cirrhosis, were randomized to receive once-daily sofosbuvir and velpatasvir $(n=134)$ or sofosbuvir plus weight-based ribavirin $(\mathrm{n}=132)$ for 12 weeks. The corresponding SVR rates were $99 \%$ and $94 \%$, respectively. ${ }^{60}$ The SVR rate with this 12 -week combination regimen without ribavirin was $100 \%$ in GT2-infected patients in the ASTRAL 1 trial. ${ }^{40}$ The ASTRAL 4 study enrolled patients with decompensated cirrhosis and reported that the SVR rate was $100 \%$ in GT2-infected patients treated with this combination, with or without ribavirin, for 12 weeks. ${ }^{41}$ Furthermore, while comparing patient reported outcomes (PROs) for the HCV patients with GT2 infection (ASTRAL 2 and 3) it was found that patients receiving the ribavirin-free regimen reported significantly better PRO scores during treatment compared with those receiving the RBV-containing regimen. ${ }^{44}$ Results from another recent international, non-randomized pilot study conducted among GT1, 2 or 4 treatmentnaïve HCV patients revealed $94 \%$ adherence to the sofosbuvir plus velpatasvir combination and reported an SVR of $90 \%$ for the GT2 HCV subtype of patients. The combination was also found to be safe and effective in HIV co-infected patients. ${ }^{50}$

\section{Sofosbuvir + ledipasvir \pm ribavirin}

In a phase III, randomized, open-label trial, the efficacy and safety of sofosbuvir and ledipasvir were assessed for the treatment of HCV GT2-infected patients with cirrhosis and/or prior treatment failure. Two cohorts of patients were considered for the study. Cohort 1 with ribavirin-tolerant eligible patients was randomized in a 1:1 ratio to receive ledipasvir plus sofosbuvir $(\mathrm{n}=106)$ or sofosbuvir plus ribavirin $(n=108)$, both for 12 weeks. Cohort 2 with patients not eligible for or intolerant to ribavirin treatment was treated with 12 weeks of ledipasvir plus sofosbuvir therapy $(\mathrm{n}=25)$. The primary endpoint of SVR 12 was achieved by $96 \%$ of patients treated with ledipasvir plus sofosbuvir, both in cohorts 1 and 2 . The treatment was well-tolerated, and no treatment-emergent resistance was noted. ${ }^{61}$

\section{Sofosbuvir + daclatasvir \pm ribavirin}

This regimen given for 24weeks was associated with an SVR of 92\% in treatment-naive HCV GT2-infected patients without cirrhosis in the AI444040 trial. ${ }^{55}$ Furthermore, daclatasvir plus sofosbuvir with ribavirin for 12 or 24 weeks was found to be safe and exhibited an $80 \%$ SVR rate in GT2-infected patients with cirrhosis in the ALLY-1 trial. ${ }^{56}$ In the ALLY-2 trial, in HCV patients co-infected with HIV-1, the overall SVR rates across GT1 through GT4 in treatment-naïve and -experienced patients treated with the 12 -week daclatasvir plus sofosbuvir regimen were noted to be $97 \%$ and $98 \%$, respectively. ${ }^{62,63}$

\section{Sofosbuvir + ribavirin}

In an international, one-arm, non-randomized study to evaluate the efficacy of a 12-week regimen of sofosbuvir and weight-based ribavirin for the treatment of treatment-naïve HCV GT 2-infected patients in West and Central Africa, an SVR rate of $90 \%$ was achieved with the combination. ${ }^{50}$ Sofosbuvir plus ribavirin for 12 weeks was associated with a $97 \%$ SVR in treatment-naive patients with GT2 infection, including in those with cirrhosis in the FISSION trial.$^{64}$ In another international, prospective, observational study, the SVR after 12 weeks of treatment with this regimen in HCV GT2 patients without and with cirrhosis was $91.0 \%$ and $79.0 \%$ respectively. ${ }^{58}$ Furthermore, this regimen was found to be effective in both treatment-naïve and treatment-experienced HCV GT2-infected patients co-infected with HIV-1 in the PHOTON 1 and 2 trials (SVR: $88 \%$ and 92\%, respectively, in PHOTON 1; SVR: $89 \%$ and $83 \%$, respectively, in PHOTON 2) ${ }^{65,66}$

\section{Treatment of Patients With HCV GT3 Infection}

The preferred and alternative regimens for the treatment of $\mathrm{HCV}$ GT3 infection are given in Table 5 . 
Table 4 Recommended treatment regimens for HCV GT2 infection

\begin{tabular}{|c|c|c|c|}
\hline \multirow[t]{2}{*}{$\begin{array}{l}\text { Recommendation } \\
\text { category }\end{array}$} & \multirow{2}{*}{$\begin{array}{l}\text { Treatment } \\
\text { option(s) } \\
\text { I. SOF+VEL } \pm \\
\text { RBV }\end{array}$} & \multicolumn{2}{|c|}{ Treatment regimen } \\
\hline & & i. & $\begin{array}{l}\text { SOF+VEL for I } 2 \text { weeks (Addition of weight-based RBV may be considered } \\
\text { for decompensated cirrhosis) }\end{array}$ \\
\hline \multirow{3}{*}{ Preferred } & $\begin{array}{l}\text { 2. } \mathrm{LDV}+\mathrm{SOF} \pm \\
\mathrm{RBV}^{\#}\end{array}$ & iii. & $\begin{array}{l}\text { LDV+SOF for I } 2 \text { weeks (Addition of RBV may be considered based on the } \\
\text { physician's discretion in treating difficult-to-treat patients [treatment-expe- } \\
\text { rienced patients, patients with cirrhosis]) } \\
\text { In case of previous SOF treatment failure: LDV+SOF+RBV for I } 2 \text { weeks }\end{array}$ \\
\hline & $\begin{array}{l}\text { 3. SOF+DCV } \pm \\
\mathrm{RBV}^{\#}\end{array}$ & $\begin{array}{l}\text { iv. } \\
\text { v. }\end{array}$ & $\begin{array}{l}\text { SOF+DCV for } 12 \text { weeks } \\
\text { In decompensated cirrhosis: SOF+DCV+RBV for } 12 \text { weeks }\end{array}$ \\
\hline & 4. SOF+RBV\# & vi. & $\begin{array}{l}\text { SOF+RBV for } 12 \text { weeks (Data are not available for patients with decompen- } \\
\text { sated cirrhosis) }\end{array}$ \\
\hline
\end{tabular}

DCV, Daclatasvir; HCV, Hepatitis C virus; GT, Genotype; RBV, Ribavirin; SOF, Sofosbuvir;VEL, Velpatasvir; LDV, Ledipasvir.

\#RBV to be dosed as per body weight

Table 5 Recommended treatment regimens for HCV GT3 infection

\begin{tabular}{l}
$\begin{array}{l}\text { Recommendation } \\
\text { category }\end{array}$ Treatment option(s) Treatment regimen \\
\hline
\end{tabular}

I. SOF+VEL $\pm \mathrm{RBV}^{\#}$

i. SOF+VEL for I2weeks (Addition of RBV may be considered based on the physician's discretion in treating difficult-to-treat patients [treatment-experienced patients, patients with cirrhosis])

ii. In patients with decompensated cirrhosis: SOF+VEL+weight-based RBV for 12 weeks

Preferred

iii. SOF+DCV for I2weeks (Addition of RBV may be considered if cirrhosis has not been conclusively ruled out)

iv. In patients with compensated cirrhosis

$\begin{array}{lll}\text { 2. SOF+DCV } \pm R B V \# & \text { v. } & \text { Treatment-naïve patients: } S O F+D C V+R B V \text { for } 12 \text { weeks } \\ \text { vi. } & \text { Treatment-experienced patients: } S O F+D C V+R B V \text { for } 24 \text { weeks }\end{array}$

vii. In patients with decompensated cirrhosis

viii. SOF+DCV+RBV for I 2 weeks

ix. If RBV ineligible: SOF+DCV for 24 weeks

I. SOF+RBV\#

Alternatives

2. $L D V+S O F+R B V^{\#}$ xi. LDV+SOF+RBV for I2weeks (should be considered only when preferred regimens are not available)

DCV, Daclatasvir; GT, Genotype; HCV, Hepatitis C virus; LDV, Ledipasvir; RBV, Ribavirin; SOF, Sofosbuvir;VEL,Velpatasvir.

\#RBV to be dosed as per body weight

Citation: Gane EJ, Charlton MR, Onyekwere CA, et al. Consensus recommendations on the diagnosis and treatment of hepatitis c virus infection in sub Saharan Africa. Gastroenterol Hepatol Open Access. 2019;10(4):18I-193. DOI: 10.15406/ghoa.2019.10.00380 


\section{Sofosbuvir + velpatasvir \pm ribavirin}

The combination regimen of sofosbuvir and velpatasvir for 12 weeks was found to be effective with 95\% SVR rates in HCV GT3-infected patients in the ASTRAL-3 trial. The SVR rate in treatment-naïve and treatment-experienced patients were $97 \%$, and $90 \%$, respectively. The SVR rate in patients with cirrhosis was $91 \%$, and in patients without cirrhosis was $97 \% .{ }^{60}$ The ASTRAL-4 study enrolled treatment-naïve and treatment-experienced patients with decompensated cirrhosis. In this study, the SVR rate with sofosbuvir and velpatasvir plus ribavirin for 12 weeks was $85 \%$ conducted among GT3-infected patients. ${ }^{41}$ In another retrospective analysis conducted in $\mathrm{HCV}$-infected patients with GT1 through GT6 infections, the SVR rate after 12weeks of treatment with sofosbuvir and velpatasvir regimen in patients with GT3 infection was found to be $95 \%$ and none of the patients in the analysis discontinued the treatment due to adverse events. Also, the combination was found to be effective in patients with advanced fibrosis and cirrhosis. ${ }^{67}$ Furthermore, sofosbuvir and velpatasvir once daily for 12 weeks has been found to be effective with a $92 \%$ SVR rate in HCV GT3-infected patients co-infected with HIV-1. ${ }^{42}$ A recent meta-analysis conducted among 2975 patients with HCV GT2 and 3 infections showed sofosbuvir combination with velpatasvir (with or without ribavirin) regimen to have a higher SVR rate at 12 weeks after the treatment with a lower adverse events rate compared to sofosbuvir combined with ribavirin (with or without peg-IFN) regimen $(94.9 \%$ versus $80.7 \%)^{68}$

\section{Sofosbuvir + daclatasvir \pm ribavirin}

The SVR rate with this regimen given for 24 weeks was $89 \%$ in treatment-naïve HCV GT3-infected patients without cirrhosis in the phase II AI444040 trial. ${ }^{55}$ In the ALLY-3 trial, the SVR rate with the 12week regimen of daclatasvir plus sofosbuvir in treatment-naïve GT3infected patients was $90 \%$, and in treatment-experienced patients, the SVR rate was $86 \% .{ }^{69}$ In the ALLY-3+ trial, the safety and efficacy of a 12- or 16-week regimen of daclatasvir plus sofosbuvir and ribavirin was assessed in both treatment-naïve and treatment-experienced GT3infected patients with advanced fibrosis or compensated cirrhosis. The overall SVR was $90 \%$. The SVR rate in the 12 -week subgroup was $88 \%$, and $83 \%$ in the 12 -week subgroup with cirrhosis. ${ }^{70}$ Furthermore, daclatasvir plus sofosbuvir with ribavirin for 12 or 24weeks exhibited an $83 \%$ SVR rate in GT3-infected patients with cirrhosis and a $91 \%$ SVR rate in GT3-infected transplant recipients in the ALLY-1 trial. ${ }^{56}$ In HCV-HIV-1 co-infected patients, the overall SVR rates across GT1 through GT4 with a 12-week regimen of daclatasvir plus sofosbuvir were noted to be $97 \%$ and $98 \%$, in treatment-naïve and treatmentexperienced patients, respectively in the ALLY-2 trial..$^{62,63}$ In one of the early access programs, daclatasvir combined with sofosbuvir, with/without ribavirin, was found to be effective in patients with life-threatening disease and high unmet needs as it provided high SVR12 rates with a good safety profile. ${ }^{59}$ In real-world settings (in the European and French compassionate programs), daclatasvir combined with sofosbuvir, with/without ribavirin has been found to be effective as well as well-tolerated in HCV GT3-infected patients, including those with prior treatment experience or with cirrhosis. ${ }^{71-74}$

\section{Sofosbuvir + ribavirin}

The regimen of sofosbuvir and ribavirin has been found to be effective in both treatment-naïve and treatment-experienced $\mathrm{HCV}$ GT3-infected patients co-infected with HIV; the overall SVR has been reported to be $89 \%$ after 12 weeks of treatment with the combination. ${ }^{66}$

\section{Sofosbuvir + ledipasvir + ribavirin}

In a phase 2, open-label trial in patients with HCV GT3 or GT6 infection, this regimen given for 12 weeks was associated with $100 \%$ SVR rate in GT3-infected patients. ${ }^{75}$ Another open-label trial revealed an overall $89 \%$ SVR with the regimen in HCV GT3-infected patients. ${ }^{76}$

\section{Treatment of patients with HCV GT4 infection}

Four treatment options have been proposed by the expert panel for the treatment of patients with HCV GT4 infection (Table 6).

\section{Sofosbuvir + velpatasvir \pm ribavirin}

Once-daily sofosbuvir and velpatasvir combination given for 12 weeks was associated with $100 \%$ SVR in GT4-infected patients in the phase III ASTRAL-1 trial. This study included both treatmentnaïve and treatment-experienced patients, including those with compensated cirrhosis. ${ }^{40}$ In the ASTRAL-4 study, which included patients with decompensated cirrhosis, sofosbuvir and velpatasvir combination for 24 weeks or for 12 weeks with or without ribavirin yielded a $100 \%$ SVR in GT4-infected patients. ${ }^{41}$ Sofosbuvir and velpatasvir combination for 12 weeks was found to be safe and was also associated with a $100 \%$ SVR in GT4-infected patients co-infected with HIV-1. ${ }^{42}$

\section{Sofosbuvir + ledipasvir + ribavirin}

Sofosbuvir and ledipasvir combination for 12 weeks resulted in a $100 \%$ SVR rate in treatment-naïve and treatment-experienced HCV GT4-infected patients, including in those with cirrhosis in the National Institute of Allergy and Infectious Diseases (NIAID) SYNERGY trial. ${ }^{77}$ High SVR rates were also noted with this regimen in other phase 2 studies in involving similar patient cohorts. ${ }^{78}$ Real-world studies also support the efficacy of this combination regimen with high SVR rates $(95.4 \%)$ in GT4-infected patients, including those with cirrhosis (SVR: $93.2 \%){ }^{79}$ In the SOLAR-2 study, sofosbuvir, ledipasvir, and ribavirin combination for 12 and 24weeks was associated with $78 \%$ and $94 \%$ SVR, respectively, in HCV GT4-infected patients with advanced liver disease ${ }^{80}$ Furthermore, in the ION-4 trial, use of the sofosbuvir and ledipasvir fixed-dose combination for 12 weeks was associated with $100 \%$ SVR in GT4-infected patients co-infected with HIV-1. This study enrolled both treatment-naïve and treatmentexperienced patients, including those with cirrhosis. ${ }^{51}$ Results from an international, non-randomized pilot study in GT4 treatment-naïve $\mathrm{HCV}$ patients revealed a $100 \%$ adherence to the sofosbuvir and ledipasvir combination and reported an SVR of $87.2 \%$ for the GT4 HCV subtype patients. The combination was also found to be safe and effective in HIV co-infected patients. ${ }^{50}$ Furthermore, the SHARED trial which evaluated the combination of sofosbuvir and ledipasvir in GT1/4 HCV patients, found an $86.7 \%$ SVR rate with the 12-week regimen. Additionally, the study showed the combination to be safe and the adherence rate to be $>98 \%{ }^{49}$

\section{Sofosbuvir + daclatasvir \pm ribavirin}

The combination of daclatasvir and sofosbuvir with ribavirin given for 12 or 24 weeks was associated with a $100 \%$ SVR in GT4infected patients with cirrhosis in the ALLY- 1 trial. ${ }^{56}$ In the ALLY-2 trial, daclatasvir plus sofosbuvir given for 12 weeks was found to be effective in treating GT1 through GT4 HCV patients co-infected with HIV-1, with $100 \%$ SVR in GT4-infected patients. ${ }^{62,63}$ 
Table 6 Recommended treatment regimens for HCV GT4 infection

\begin{tabular}{lll}
\hline $\begin{array}{l}\text { Recommendation } \\
\text { category }\end{array}$ & $\begin{array}{l}\text { Treatment } \\
\text { option(s) }\end{array}$ & Treatment regimen \\
\hline
\end{tabular}

I. SOF+VEL \pm RBV\#

2. $\mathrm{LDV}+\mathrm{SOF} \pm$ RBV\# i. SOF+VEL for I2weeks (Addition of RBV may be considered based on the physician's discretion in treating difficult-to-treat patients [treatment-experienced patients, patients with cirrhosis])

ii. In patients with decompensated cirrhosis: SOF+VEL+weight-based RBV for 12 weeks

Preferred

iii. LDV+SOF for 12 weeks (Addition of RBV may be considered based on the physician's discretion in treating difficult-to-treat patients [treatment-experienced patients, patients with cirrhosis])

iv. In case of previous SOF treatment failure: LDV+SOF+RBV for 12 weeks

Alternatives $\quad$ SOF+DCV \pm
V. SOF+DCV for I2 weeks (Addition of RBV may be considered if cirrhosis has not been conclusively ruled out)

vi. Cirrhosis of any class: SOF+DCV+RBV for I 2 weeks

vii. If RBV is ineligible, SOF+DCV for 24 weeks

DCV, daclatasvir; GT, genotype; HCV, hepatitis C virus; LDV, ledipasvir; RBV, ribavirin; SOF, sofosbuvir;VEL, velpatasvir.

\#RBV to be dosed as per body weight

\section{Treatment of patients with HCV GT5 or GT6 infections}

The preferred and alternative regimens for the treatment of $\mathrm{HCV}$ GT5 or GT6 infections are given in Table 7.

\section{Sofosbuvir + velpatasvir \pm ribavirin}

In the ASTRAL-1 study, treatment with once-daily sofosbuvir and velpatasvir for 12 weeks was associated with $97 \%$ and $100 \%$ SVR rates in patients with GT5 and GT6 infections, respectively. ${ }^{40}$ In a separate phase 2 study, the SVR rate with this combination was 95\%-96\% for GT5- and GT6-infected patients. ${ }^{81}$ Furthermore, treatment with sofosbuvir and velpatasvir for 24weeks in patients with GT6 infection was associated with $100 \%$ SVR rate in the ASTRAL-4 study. ${ }^{41}$

\section{Sofosbuvir + ledipasvir \pm ribavirin}

Treatment with the sofosbuvir and ledipasvir regimen for 12 weeks in GT5-infected treatment-naïve and treatment-experienced patients, including those with cirrhosis, has been found to be safe and associated with a $95 \%$ SVR rate. ${ }^{82}$ In a separate study, in patients with GT3 or GT6 infection, treatment-naïve and treatment-experienced patients with GT6 infection $(n=25)$ treated with the combination for 12 weeks attained a $96 \%$ SVR rate. $^{75}$

\section{Sofosbuvir + daclatasvir \pm ribavirin}

The ALLY-1 trial evaluated sofosbuvir, daclatasvir, and ribavirin combination across all genotypes in HCV patients with advanced liver disease. Sustained virologic response was achieved in one GT6infected liver transplant recipient treated with the combination. ${ }^{56}$

\section{Treatment of patients in situations where GT testing is not available}

The pan-genotypic velpatasvir regimens recommended by the Expert Panel for the treatment of HCV-infected patients in situations where GT testing is not available, include: (1) sofosbuvir plus velpatasvir for 12 weeks in treatment naïve noncirrhotic patients; (2) sofosbuvir plus velpatasvir with/without ribavirin for 12 weeks in treatment (Peg-IFN)-experienced noncirrhotic patients; (3) sofosbuvir plus velpatasvir for 12 weeks in treatment naïve cirrhotic patients; (4) sofosbuvir plus velpatasvir with/without ribavirin for 12 weeks in treatment (Peg-IFN)-experienced cirrhotic patients; and (5) sofosbuvir plus velpatasvir with ribavirin for 12 weeks in decompensated cirrhotic patients. 
Table 7. Recommended treatment regimens for HCV GT5 or GT6 infections

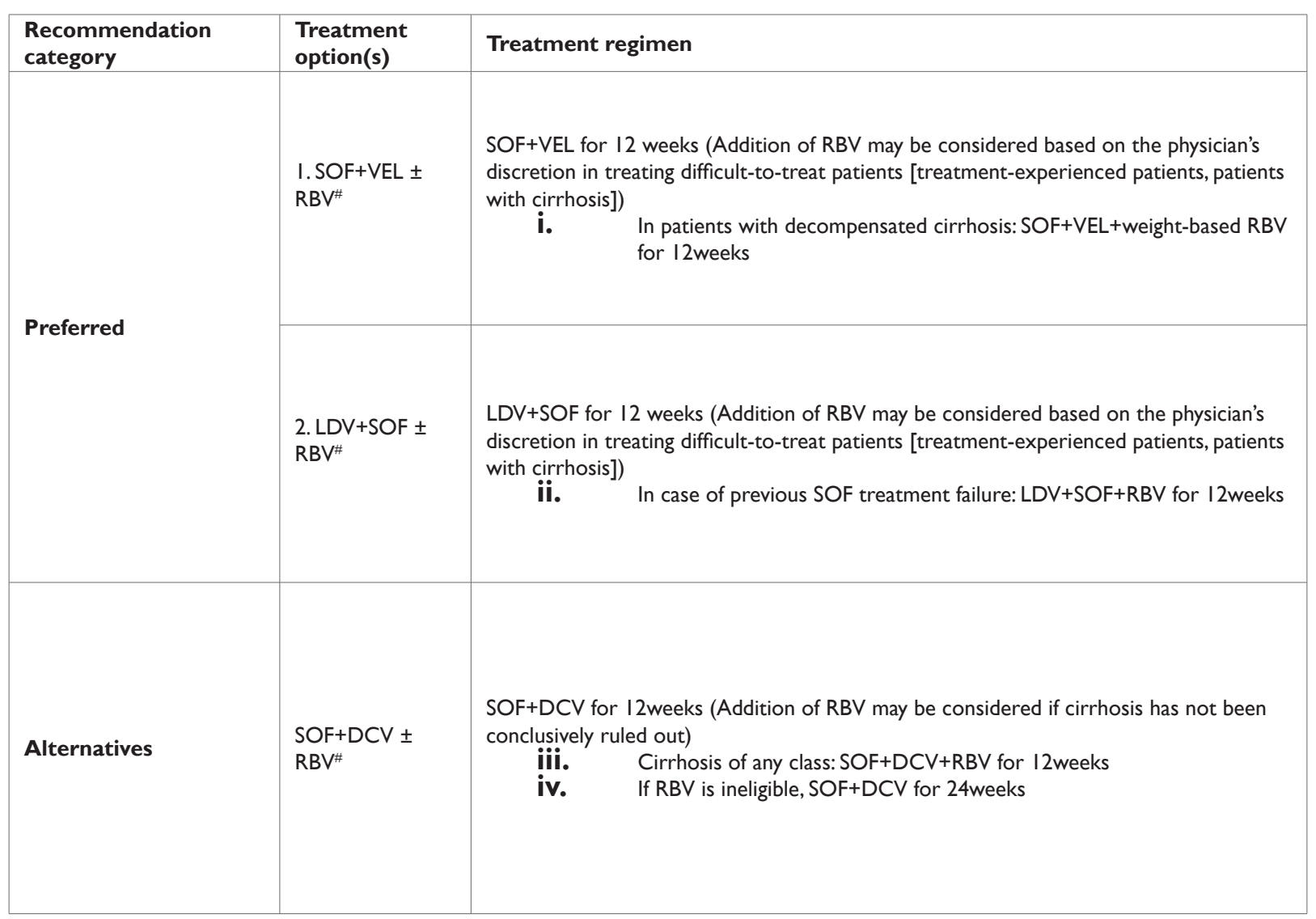

DCV, daclatasvir; HCV, hepatitis C virus; GT, genotype; LDV, ledipasvir; RBV, ribavirin; SOF, sofosbuvir;VEL, velpatasvir.

\#RBV to be dosed as per body weight

\section{On- and post-treatment assessments}

Assessing the on-treatment efficacy and safety, monitoring drugdrug interactions, and evaluating medication adherence are crucial for achieving better treatment outcomes during the management of HCV infection. Conducting optimal follow-up and assessments post-treatment helps establish the successful elimination of the virus and prevents relapses. The on- and post-treatment assessments recommended by the expert panel are listed in Table 8 .

Table 8 On- and post-treatment assessments during the management of $\mathrm{HCV}$ infection

\section{Assessments Expert recommendations}

i. In patients with cirrhosis, $\mathrm{CBC}$, creatinine level, calculated GFR, and hepatic function panel may be repeated after 4 weeks.

ii. All patients on RBV should have $\mathrm{CBC}$ done at 4 and 8 weeks to monitor for hemolysis.

On-treatment iii. HCV RNA testing (qualitative/quantitative) is not required, as there are no current recommendations for response-guided therapy. Testing may be done at the end of treatment, but it is not mandatory.

iv. Assessment of potential drug-drug interactions with concomitant medications is recommended.

V. Periodic reviews of therapy compliance and the general condition of the patient are recommended. 
Table Continued

\begin{tabular}{|c|c|}
\hline \multirow[t]{2}{*}{ Assessments } & Expert recommendations \\
\hline & $\begin{array}{l}\text { i. Assessment for SVR should be done at I } 2 \text { weeks or later after the end of the treatment. } \\
\text { ii. In patients who have failed therapy: } \\
\text { a. } \\
\text { months. Disease progression assessment (hepatic function panel, CBC, and INR) should be done once in } 6 \text { to } 12 \\
\text { b. In patients with advanced fibrosis (Metavir stages F3 or F4), screening for hepatocellular carcinoma with } \\
\text { ultrasound examination is recommended every } 6 \text { months. }\end{array}$ \\
\hline Post-treatment & $\begin{array}{l}\text { C. Endoscopic screening for esophageal varices is recommended in cirrhotic patients with evidence of varices } \\
\text { before treatment. } \\
\text { iii. In patients who achieve SVR: } \\
\text { a. In patients with advanced fibrosis (Metavir stage F3 or F4), screening for hepatocellular carcinoma with } \\
\text { ultrasound examination is recommended every } 6 \text { months. } \\
\text { b. } \quad \text { Endoscopic screening for esophageal varices is recommended in cirrhotic patients. } \\
\text { c. } \quad \text { AFP as a screening test for HCC is recommended in cirrhotic patients }\end{array}$ \\
\hline
\end{tabular}

CBC, complete blood count; GFR, glomerular filtration rate; HCV, hepatitis C virus; INR, international normalized ratio; RNA, ribonucleic acid; SVR, sustained virologic response; AFP, alpha fetoprotein; HCC, hepatocellular carcinoma.

\section{Summary and future directives}

One of the major unmet needs in Africa is the need for developing structured region-specific guidelines on the diagnosis and treatment of $\mathrm{HCV}$ infection that can help guide clinical practice decisions. The current African consensus document aims to provide necessary guidance to the clinicians practicing in the region for the costeffective and optimal management of HCV infection. The document encapsulates the key recommendations from the expert panel on the diagnosis, screening, and treatment of $\mathrm{HCV}$ infection along with summarizing, the pre-, on-, and post-treatment assessment of patients with $\mathrm{HCV}$ infection in Africa. In addition to translating these evidencebased recommendations to clinical practice, it is imperative that physicians in this region individualize and optimize the management of $\mathrm{HCV}$ infection and contribute to enhancing the patients' awareness of the disease. Improving access to newer and safer treatments may also help in further optimization of treatment outcomes in resourcelimited settings such as Africa.

\section{Acknowledgements}

We would like to thank Mylan Pharmaceuticals ltd for financial support in execution of this project. We would also like to thank BioQuest Solutions Ltd for providing writing assistance.

\section{Conflicts of interests}

Author Edward John Gane: Member of Clinical Advisory Board for Gilead Sciences, AbbVie, Janssen, Arrowhead, Merck, VIR Biotechnology, and Assembly Bio. Member of Speakers' Bureau for Gilead Sciences, AbbVie, Mylan Pharmaceuticals

Author Michael Charlton: Consulting and research support for Gilead Sciences, Merck, AbbVie, Novartis and Only consulting support for Mylan

Author Nadia Jacqueline Mandeng: Transport and accommodation in the consensus building meetings was provided by Mylan

Author Ravishankar AC: Employee of Mylan Pharmaceuticals Private Limited

Author Sanjay Hadigal: Employee of Mylan Pharmaceuticals Private Limited

\section{Funding information}

The project is supported by Mylan Pharmaceuticals Ltd.

\section{References}

1. ICTV master species list 2016 (MSL31) v1.3.

2. Hepatitis C-Fact Sheet. World Health Organization 2017.

3. Smith DB, Bukh J, Kuiken C, et al. Expanded classification of Hepatitis $\mathrm{C}$ virus into 7 genotypes and 67 subtypes: Updated criteria and genotype assignment web resource. Hepatology. 2014;59(1):318-327.

4. Murphy DG, Sablon E, Chamberland J, et al. Hepatitis C virus genotype 7, a new genotype originating from central Africa. J Clin Microbiol. 2015;53(3):967-972.

5. World Health Organization. Global Hepatitis Report. Geneva: World Health Organization; 2017. World Health Organization. Blach S, Zeuzem S, Manns M, et al. Global prevalence and genotype distribution of Hepatitis C virus infection in 2015: A modelling study. Lancet Gastroenterol Hepatol. 2017;2(3):161-176.

6. Riou J, Ahmed MA, Blake A, et al. Hepatitis C virus seroprevalence in adults in Africa: A systematic review and meta-analysis. J Viral Hepat. 2016;23(4):244-255.

7. Agyeman AA, Asenso RO, Mprah A, et al. Epidemiology of hepatitis C virus in Ghana:A systematic review and meta-analysis. BMC Infectious Disease. 2016;16:391.

8. Bigna JJ, Amougou MA, Asangbeh SL, et al. Seroprevalence of hepatitis $\mathrm{C}$ virus infection in Cameroon: A systematic review and meta-analysis. BMJ Open. 2017;7(8):e015748.

9. Petruzziello A, Marigliano S, Loquercio G, et al. Global epidemiology of hepatitis $\mathrm{C}$ virus infection: An up-date of the distribution and circulation of hepatitis C virus genotypes. World J Gastroenterol. 2016;22(34):7824 7840 .

10. Asselah T, Hassanein T, Waked I, et al. Eliminating hepatitis $\mathrm{C}$ within low-income countries - The need to cure genotypes 4, 5, 6. J Hepatol. 2018;68(4):814-826.

11. Daw MA, El-Bouzedi A, Ahmed MO, et al. Hepatitis C virus in North Africa: An emerging threat. Sci World J. 2016;2016:1-11.

12. Gededzha MP, Mphahlele MJ, Blackard JT, et al. Prevalence of NS5B resistance mutations in Hepatitis C Virus ( HCV ) treatment naive South Africans. Hepat Mon. 2017;17(6): e14248. 
13. Burstow NJ, Mohamed Z, Gomaa AI, et al. Hepatitis C treatment: where are we now? Int J Gen Med. 2017;10:39-52.

14. Heffernan A, Barber E, Cook NA, et al. Aiming at the global elimination of viral hepatitis: Challenges along the care continuum. Open Forum Infect Dis. 2018;5(1):1-6.

15. Assefa Y, Hill PS, Ulikpan A, et al. Access to medicines and hepatitis $\mathrm{C}$ in Africa: Can tiered pricing and voluntary licencing assure universal access, health equity and fairness? Global Health. 2017;13(1):1-11.

16. Suthar AB, Harries AD. A public health approach to hepatitis $\mathrm{C}$ contro in low and middle-income countries. PLoS Med. 2015;12(3):e1001795.

17. http://documents.worldbank.org/curated/en/335981517329520478/ pdf/123067-WP-PUBLIC-P157533-Treatment-Program-PolicyAnalysi.pdf

18. Sonderup MW, Afihene M, Ally R, et al. Hepatitis C in sub-Saharan Africa: the current status and recommendations for achieving elimination by 2030. Lancet Gastroenterol Hepatol. 2017;2(12):910-919.

19. Vermehren J, Park JS, Jacobson I, et al. Challenges and perspectives of direct antivirals for the treatment of hepatitis $\mathrm{C}$ virus infection. $J$ Hepatol. 2018;69(5):1178-1187

20. HCV guidance: Recommendations for testing, managing, and treating Hepatitis C. The American Association for the Study of Liver Diseases and the Infectious Diseases Society of America 2018.

21. European Association for the Study of the Liver. EASL recommendations on treatment of Hepatitis C 2018. J Hepatol. 2018; 69(2):461-511.

22. http://www.who.int/hepatitis/publications/hepatitis-c-guidelines-2016/ en/.

23. Botha JF, Kassianides C, Schneider HR, et al. South African Hepatitis C Management Guidelines 2010. South African Gastroenterol Rev. 2010;8(1):20-25.

24. https://www.who.int/news-room/fact-sheets/detail/hepatitis-c

25. Goel A, Chen Q, Chhatwal J, et al. Cost-effectiveness of generic pangenotypic sofosbuvir/velpatasvir versus genotype-dependent directacting antivirals for hepatitis C treatment. $J$ Gastroenterol Hepatol. 2018;33(12):2029-2036.

26. Zeba MT, Karou SD, Sagna T, et al. HCV prevalence and co-infection with HIV among pregnant women in Saint Camille Medical Centre, Ouagadougou. Trop Med Int Health. 2011;16(11):1392-1396.

27. Kodjoh N. Fighting viral hepatitis B and C in Africa. Focus on Benin. Med Sante Trop. 2015;25(2):141-144.

28. Jamma S, Hussain G, Lau DTY. Current concepts of HBV/HCV coinfection: Coexistence, but not necessarily in harmony. Curr Hepat Rep. 2010;9(4):260-269.

29. Konstantinou D, Deutsch M. The spectrum of HBV/HCV coinfection Epidemiology, clinical characteristics, viral interactions and management Ann Gastroenterol. 2015;28(2):221-228.

30. Calvaruso V, Craxì A. HBV recurrence after HCV clearance on DAAs Sometimes they come back. J Hepatol. 2017;67(5):898-901.

31. Aggeletopoulou I, Konstantakis C, Manolakopoulos S, et al. Risk of hepatitis B reactivation in patients treated with direct-acting antivirals for hepatitis C. World J Gastroenterol. 2017;23(24):4317-4323.

32. Mucke MM, Backus LI, Mucke VT, et al. Hepatitis B virus reactivation during direct-acting antiviral therapy for hepatitis C: A systematic review and meta-analysis. Lancet Gastroenterol Hepatol. 2018;3(3):172-180.

33. Serag HB, Davila JA. Surveillance for hepatocellular carcinoma: In whom and how? Therap Adv Gastroenterol. 2011;4(1):5-10.

34. Sofosbuvir tablets for oral use. 2018

35. https://www.accessdata.fda.gov/drugsatfda_docs/ label/2014/205834s0001bl.pdf

36. https://www.accessdata.fda.gov/drugsatfda docs/ label/2016/208341s0001bl.pdf

37. https://www.accessdata.fda.gov/drugsatfda docs label/2015/206843Orig1s0001bl.pdf

38. https://www.accessdata.fda.gov/drugsatfda docs/ label/2011/021511s023lbl.pdf

39. Feld JJ, Jacobson IM, Hézode C, et al. Sofosbuvir and Velpatasvir for HCV Genotype 1, 2, 4, 5, and 6 Infection. N Engl J Med. 2015;373(27):25992607

40. Curry MP, O’Leary JG, Bzowej N, et al. Sofosbuvir and Velpatasvir for $\mathrm{HCV}$ in patients with decompensated cirrhosis. $N$ Engl J Med. 2015;373(27):2618-2628.

41. Wyles D, Bräu N, Kottilil S et al. Sofosbuvir and Velpatasvir for the treatment of $\mathrm{HCV}$ in patients coinfected with HIV-1: An open-label, Phase 3 Study. Clin Infect Dis. 2017;65(1):6-12.

42. Yang YM, Choi EJ. Efficacy and safety outcomes of sofosbuvir-based treatment regimens for hepatitis $\mathrm{C}$ virus-infected patients with or without cirrhosis from phase III clinical trials. Ther Clin Risk Manag. 2017; 13:477-497.

43. Younossi ZM, Stepanova M, Sulkowski M, et al. Ribavirin-free regimen with Sofosbuvir and Velpatasvir is associated with high efficacy and improvement of patient-reported outcomes in patients with genotypes 2 and 3 chronic Hepatitis C: Results from Astral-2 and -3 clinical trials. Clin Infect Dis. 2016;63(8):1042-1048.

44. Afdhal N, Zeuzem S, Kwo P, et al. Ledipasvir and Sofosbuvir for untreated HCV genotype 1 infection. N Engl J Med. 2014;370(20):1889-1898.

45. Kowdley KV, Gordon SC, Reddy KR, et al. Ledipasvir and Sofosbuvir for 8 or 12 weeks for chronic HCV without cirrhosis. $N$ Engl J Med. 2014;370(20):1879-1888

46. Gerber L, Estep M, Stepanova M, et al. Effects of Viral Eradication With Ledipasvir and Sofosbuvir, With or Without Ribavirin, on Measures of Fatigue in Patients With Chronic Hepatitis C Virus Infection. Clin Gastroenterol Hepatol. 2016;14(1):156-164.e3.

47. Moon J, Hyland RH, Zhang F, et al. Efficacy and safety of Ledipasvir/ Sofosbuvir for the treatment of chronic Hepatitis $\mathrm{C}$ in persons with sickle cell disease. Clin Infect Dis. 2017;65(5):864-866.

48. Gupta N, Kabahizi J, Muvunyi C, et al. Direct-acting antiviral treatment in sub-Saharan Africa: A prospective trial of Ledipasvir/Sofosbuvir for chronic Hepatitis C infection in Rwanda (the SHARED study). J Hepatol. 2018;68(18):30320-30329.

49. Lacombe K, Moh R, Chazallon C, et al. Treatment of chronic Hepatitis C GT1, 2, 4 in Africa: Final results of ANRS 12311 TAC trial. 2018:75571.

50. Naggie S, Cooper C, Saag M, et al. Ledipasvir and Sofosbuvir for HCV in patients coinfected with HIV-1. N Engl J Med. 2015;373(8):705-713.

51. Afdhal N, Reddy KR, Nelson DR, et al. Ledipasvir and Sofosbuvir for previously treated $\mathrm{HCV}$ Genotype 1 infection. $N$ Engl J Med. 2014;370(16):1483-1493.

52. Bourlière M, Bronowicki JP, de Ledinghen V, et al. Ledipasvir-sofosbuvir with or without ribavirin to treat patients with $\mathrm{HCV}$ genotype 1 infection and cirrhosis non-responsive to previous protease-inhibitor therapy: A randomised, double-blind, phase 2 trial (SIRIUS). Lancet Infect Dis. 2015;15(4):397-404.

53. Tao T, Jiang X, Chen Y, et al. Efficacy and Safety of Ledipasvir/Sofosbuvir with and without Ribavirin in patients with chronic Hepatitis C Virus Genotype 1 infection: A meta-analysis. Int J Infect Dis. 2017;55:56-71.

54. Sulkowski MS, Gardiner DF, Rodriguez-Torres M, et al. Daclatasvir plus Sofosbuvir for previously treated or untreated chronic HCV infection. $N$ Engl J Med. 2014;370(3):211-221. 
55. Poordad F, Schiff ER, Vierling JM, et al. Daclatasvir with sofosbuvir and ribavirin for hepatitis $\mathrm{C}$ virus infection with advanced cirrhosis or postliver transplantation recurrence. Hepatology. 2016;63(5):1493-1505.

56. Castells L, Llaneras J, Campos-varela I, et al. Sofosbuvir and Daclatasvir in Mono- and HIV-coinfected patients with recurrent Hepatitis C after liver transplant. Ann Hepatol. 2017;16(1):86-93.

57. Welzel TM, Petersen J, Herzer K, et al. Daclatasvir plus sofosbuvir, with or without ribavirin, achieved high sustained virological response rates in patients with HCV infection and advanced liver disease in a real-world cohort. Gut. 2016;65(11):1861-1870.

58. Kwo P, Fried MW, Reddy KR, et al. Daclatasvir and sofosbuvir treatment of decompensated liver disease or post-liver transplant hepatitis $C$ virus recurrence in patients with advanced liver disease/cirrhosis in a realworld cohort. Hepatol Commun. 2018;2(4):354-363.

59. Foster GR, Afdhal N, Roberts SK, et al. Sofosbuvir and Velpatasvir for HCV Genotype 2 and 3 Infection. N Engl J Med. 2015;373(27):26082617.

60. Asahina Y, Itoh Y, Ueno Y, et al. Ledipasvir/sofosbuvir in the treatment of Japanese patients with chronic HCV genotype 2 infection. Liver Int. 2018;38(9):1552-1561.

61. Wyles DL, Ruane PJ, Sulkowski MS, et al. Daclatasvir plus Sofosbuvir for HCV in patients coinfected with HIV-1. NEngl J Med. 2015;373(8):714 725 .

62. Luetkemeyer AF, McDonald C, Ramgopal M, et al. 12 Weeks of Daclatasvir in combination with Sofosbuvir for HIV-HCV coinfection (ALLY-2 Study): Efficacy and safety by HIV combination antiretroviral regimens. Clin Infect Dis. 2016;62(12):1489-1496.

63. Lawitz E, Mangia A, Wyles D, et al. Sofosbuvir for previously untreated chronic Hepatitis C infection. N Engl J Med. 2013;368(20):1878-1887.

64. Sulkowski MS, Naggie S, Lalezari J, et al. Sofosbuvir and Ribavirin for Hepatitis C in patients with HIV-1 coinfection. JAMA. 2014;312(4): $353-361$.

65. Molina JM, Orkin C, Iser DM, et al. Sofosbuvir plus ribavirin for treatment of hepatitis $\mathrm{C}$ virus in patients co-infected with HIV (PHOTON-2): a multicentre, open-label, non-randomised, phase 3 study. Lancet. 2015;385(9973):1098-1106.

66. Asselah T, Bourgeois S, Pianko S, et al. Sofosbuvir/velpatasvir in patients with hepatitis $\mathrm{C}$ virus genotypes 1-6 and compensated cirrhosis or advanced fibrosis. Liver Int. 2018;38(3):443-450.

67. Fan H, Huang P, Tian T, et al. Efficacy and safety of sofosbuvircontaining regimens in chronic hepatitis $\mathrm{C}$ patients with genotype 2 and 3: a comprehensive analysis of 18 randomized controlled trials. $J$ Gastrointestin Liver Dis. 2018;27(2):159-168.

68. Nelson DR, Cooper JN, Lalezari JP, et al. All-oral 12-week treatment with Daclatasvir plus Sofosbuvir in patients with Hepatitis C virus Genotype 3 infection: ALLY-3 Phase III Study. Hepatology. 2015;61(4):1127-1135.
69. Leroy V, Angus P, Bronowicki JP, et al. Daclatasvir, Sofosbuvir, and Ribavirin for Hepatitis C virus Genotype 3 and advanced liver disease: A randomized Phase III Study (ALLY-31). Hepatology. 2016;63(5):1430 1441

70. Hézode C, De Ledinghen V, Fontaine H, et al. Daclatasvir plus sofosbuvi with or without ribavirin in patients with HCV genotype 3 infection: Interim analysis of a French multicenter compassionate use program. $J$ Hepatol. 2015;62(Suppl. 2):S265-S266.

71. Leroy V, Hezode C, Metivier S, et al. Daclatasvir plus sofosbuvir with or without ribavirin in patients with $\mathrm{HCV}$ infection and decompensated cirrhosis: Interim analysis of a French multicentre compassionate use programme. J Hepatol. 2016;64(2):S829.

72. Hézode C, Lebray P, De Ledinghen V, et al. Daclatasvir plus sofosbuvir, with or without ribavirin, for hepatitis $\mathrm{C}$ virus genotype 3 in a French early access programme. Liver Int. 2017;37(9):1314-1324.

73. Petersen J, Welzel TM, Herzer K, et al. Daclatasvir plus sofosbuvir with or without ribavirin for the treatment of chronic HCV infection in patients with decompensated cirrhosis: Results of a European multicentre compassionate use programme. J Hepatol. 2016;64(2):S781-S782.

74. Gane EJ, Hyland RH, An D, et al. Efficacy of ledipasvir and sofosbuvir, with or without ribavirin, for 12 weeks in patients with HCV genotype 3 or 6 infection. Gastroenterology. 2015;149(6):1454-1461.

75. Feld JJ, Ramji A, Shafran SD, et al. Ledipasvir-Sofosbuvir plus Ribavirin in treatment-naive patients with Hepatitis C Virus Genotype 3 infection: An open-label study. Clin Infect Dis. 2017;65(1):13-19.

76. Kohli A, Kapoor R, Sims Z, et al. Ledipasvir and sofosbuvir for hepatitis C genotype 4: a proof-of-concept, single-centre, open-label phase $2 \mathrm{a}$ cohort study. Lancet Infect Dis. 2015;15(9):1049-1054.

77. Abergel A, Metivier S, Samuel D, et al. Ledipasvir plus sofosbuvir for 12 weeks in patients with hepatitis $\mathrm{C}$ genotype 4 infection. Hepatology. 2016;64(4):1049-1056.

78. Crespo J, Calleja JL, Fernández I, et al. Real-World Effectiveness and Safety of Oral Combination Antiviral Therapy for Hepatitis C Virus Genotype 4 Infection. Clin Gastroenterol Hepatol. 2017;15(6):945-949.

79. Manns M, Samuel D, Gane EJ, et al. Ledipasvir and sofosbuvir plus ribavirin in patients with genotype 1 or 4 hepatitis $\mathrm{C}$ virus infection and advanced liver disease: a multicentre, open-label, randomised, phase 2 trial. Lancet Infect Dis. 2016;16(6):685-697.

80. Everson GT, Towner WJ, Davis MN, et al. Sofosbuvir with Velpatasvir in treatment-naive noncirrhotic patients with Genotype 1 to 6 Hepatitis C virus infection: A randomized trial. Ann Intern Med. 2015;163(11):818 826.

81. Abergel A, Asselah T, Metivier S, et al. Ledipasvir-sofosbuvir in patients with hepatitis $\mathrm{C}$ virus genotype 5 infection: an open-label, multicentre, single-arm, phase 2 study. Lancet Infect Dis. 2016;16(4):459-464. 